\title{
Effect of Dam Depth and Relief Track Depth on Steady-State and Dynamic Performance Parameters of 3-Lobe Pressure Dam Bearing
}

\author{
Ashutosh Kumar and S. K. Kakoty \\ Indian Institute of Technology Guwahati, Guwahati, India \\ Correspondence should be addressed to Ashutosh Kumar; ashutosh.mech@iitg.ernet.in
}

Received 18 October 2016; Accepted 31 January 2017; Published 14 March 2017

Academic Editor: GunHee Jang

Copyright ( 2017 Ashutosh Kumar and S. K. Kakoty. This is an open access article distributed under the Creative Commons Attribution License, which permits unrestricted use, distribution, and reproduction in any medium, provided the original work is properly cited.

\begin{abstract}
The present study analyzes the effect of pressure dam depth and relief track depth on the performance of three-lobe pressure dam bearing. Different values of dam depth and relief track depth are taken in nondimensional form in order to analyze their effect. Results are plotted for different parameters against eccentricity ratios and it is shown that the effect of pressure dam depth and relief track depth has great significance on stability and other performance parameters. Study of stability and performance characteristics is undertaken simultaneously.
\end{abstract}

\section{Introduction}

In present time, the industry is required to run the turbomachines for long time at high speeds. The most commonly used cylindrical bearings are found to be unstable at high speed. It is found that stability can be increased by using noncircular bearing instead of circular bearing. Further, use of pressure dam makes the bearing very stable at high speeds. The stability analysis of finite length bearing was carried out by Nicholas and Allaire [1]. Nicholas et al. [2] reported experimental whirl frequency ratio (WFR) for near optimum pressure dam bearings supporting flexible rotors. The effect of ellipticity ratio on the performance of displaced centre bearing is observed and found that there is an increase in vertical stiffness with increase in ellipticity [3]. Performance analysis of three-lobe pressure dam bearing was carried out by Mehta and Rattan [4] and found that it has very high value of minimum threshold speed and zone of infinite stability. The relief track width is one of the important parameters that affect the performance of pressure dam bearings. Lund and Thomson [5] had done the analysis of steady-state and dynamic characteristics of grooved, two-lobe, and three-lobe bearings and presented the result in tabular form. In the same line, Soni et al. [6] studied two-lobe journal bearing using linearized turbulent lubrication theory by FEM and Galerkin's technique.

Kumar et al. [7] had done the detail study and analysis of two-lobe pressure bearing and shown the superiority of these bearings over conventional circular bearing. Static and dynamic characteristics of orthogonally displaced pressure dam bearing had been studied by Mehta [8]. Mehta and Singh [9] studied the dynamic behavior of offset half pressure dam bearing. Effect of micropolar lubrication couple stress fluids on two-lobe and multilobe pressure dam bearing was studied by many researchers. In this line, Sharma and Ratan [10] studied the performance of two-lobe pressure dam bearings under micropolar fluid lubrication and found an increase in load carrying capacity.

From the available literature, it has been proven that incorporation of pressure dam and relief track is useful in improving the stability of a multilobe pressure dam bearing. So, the pressure dam depth, relief track depth, pressure dam axial width, relief track axial width, pressure dam circumferential length, and relief track circumferential length are supposed to have great influence on static and dynamic behaviors of two-lobe and multilobe pressure dam bearings. Therefore, the present study has been undertaken to investigate the effect of pressure dam depth and relief track 


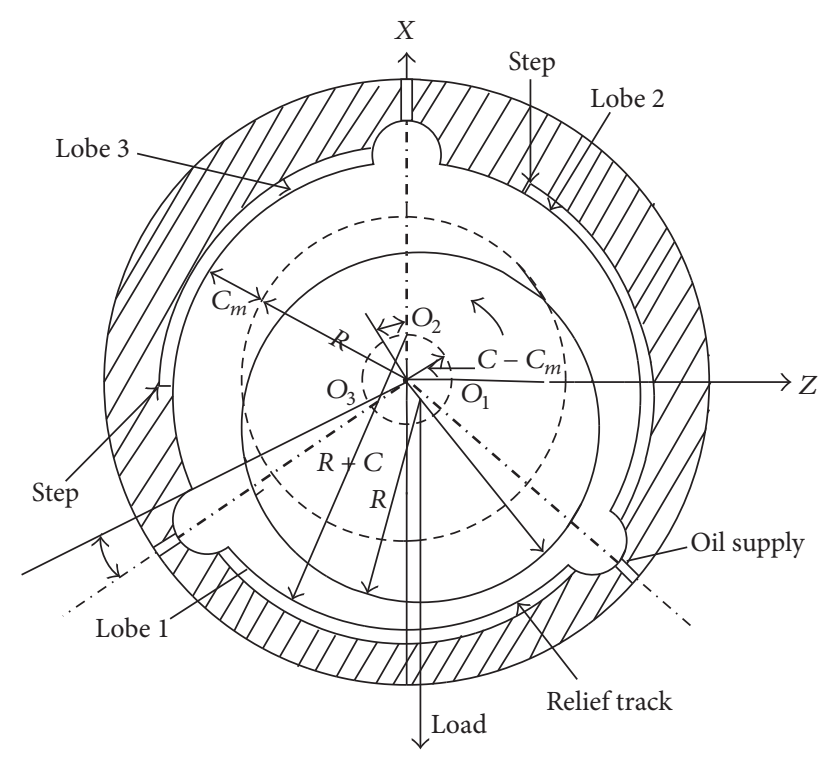

FIGURE 1: Three-lobe pressure dam bearing.

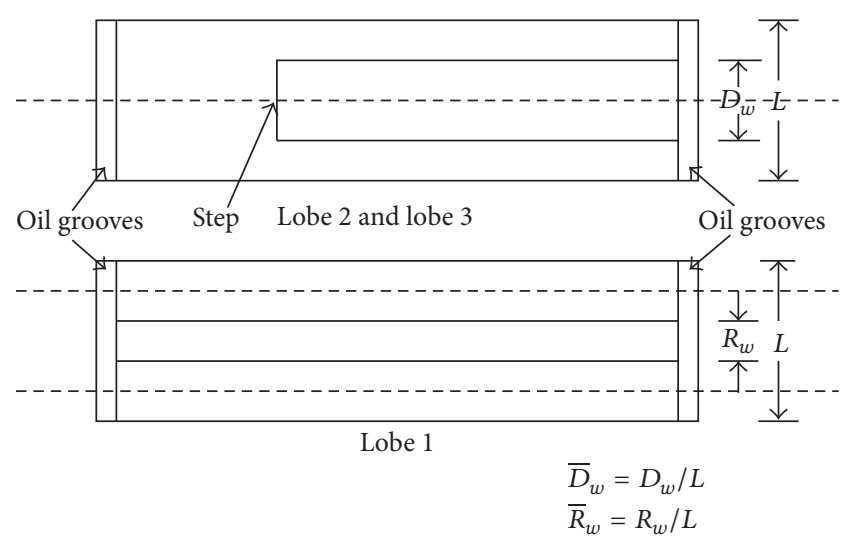

FIGURE 2: Individual lobes of three-lobe pressure dam bearing.

depth on the steady-state and dynamic characteristics of twolobe and three-lobe pressure dam bearings.

\section{Theory}

Figure 1 shows the schematic diagram of three-lobe pressure dam bearing, whereas Figure 2 shows different lobes with pressure dam and relief track. $O_{1}, O_{2}$, and $O_{3}$ are the center of lobes 1,2, and 3, respectively. Each lobe of the bearing is circular but the geometric configuration of the bearing is not. Lobe 2 and lobe 3 are provided with a rectangular pressure dam of depth $D_{d}$ and width (axial length) $D_{w}$. Similarly, lobe 1 is provided with relief track of depth $R_{d}$ and width $R_{w}$. Each dam subtends an angle of $90^{\circ}$ at the center starting from the beginning of the individual lobe. Bearing is provided with three oil supply holes of $10^{\circ}$ at $0^{\circ}, 120^{\circ}$, and $240^{\circ}$. Two different clearances are shown: a minor clearance $\left(C_{m}\right)$ for the centered shaft and a major clearance $(C)$ for the circle circumscribed by the lobe radius. So, the center of each lobe is shifted by a distance $e_{p}$, which is given by $e_{p}=C-C_{m}$, and this $e_{p}$ is nondimensionalized by dividing it by major radial clearance (C) which is known as ellipticity ratio; that is, $\delta=e_{p} / C=$ $1-C_{m} / C$.

From the geometry, eccentricity ratios of individual lobes are given as

$$
\begin{aligned}
& \varepsilon_{1}=\sqrt{\varepsilon^{2}+\delta^{2}+2 \varepsilon \delta \cos (\phi)} \\
& \varepsilon_{2}=\sqrt{\varepsilon^{2}+\delta^{2}-2 \varepsilon \delta \cos \left(\frac{\pi}{3}+\phi\right)} ; \\
& \varepsilon_{3}=\sqrt{\varepsilon^{2}+\delta^{2}-2 \varepsilon \delta \cos \left(\frac{\pi}{3}-\phi\right)} .
\end{aligned}
$$

Similarly, attitude angles of individual lobes are given as

$$
\begin{aligned}
& \phi_{1}=\tan ^{-1}\left(\frac{\varepsilon \sin \phi}{\delta+\varepsilon \cos \phi}\right) ; \\
& \phi_{2}=\frac{2 \pi}{3}-\tan ^{-1}\left(\frac{\varepsilon \sin (\pi / 3+\phi)}{\delta-\varepsilon \cos (\pi / 3+\phi)}\right), \\
& \phi_{3}=-\left(\frac{2 \pi}{3}-\tan ^{-1}\left(\frac{\varepsilon \sin (\pi / 3-\phi)}{\delta-\varepsilon \cos (\pi / 3-\phi)}\right)\right) .
\end{aligned}
$$

Reynolds equation for incompressible, nonviscous laminar flow for hydrodynamic lubrication is given as

$$
\frac{\partial}{\partial x}\left(h^{3} \frac{\partial p}{\partial x}\right)+\frac{\partial}{\partial z}\left(h^{3} \frac{\partial p}{\partial z}\right)=6 \eta U \frac{\partial h}{\partial x}+12 \eta \frac{\partial h}{\partial t}
$$

This equation in nondimensionalized (by using substitutions) form is given as

$$
\frac{\partial}{\partial \theta}\left(\bar{h}^{3} \frac{\partial \bar{p}}{\partial \theta}\right)+\left(\frac{D}{L}\right)^{2} \frac{\partial}{\partial \bar{z}}\left(\bar{h}^{3} \frac{\partial \bar{p}}{\partial \bar{z}}\right)=\frac{d \bar{h}}{d \theta}+2 \lambda \frac{\partial \bar{h}}{\partial \tau} .
$$

Equation (2) is the nondimensional Reynolds equation for dynamic state condition. Let $\varepsilon_{0}$ and $\phi_{0}$ be the steady-state eccentricity ratio and attitude angle, respectively. Now, considering that the journal whirls with small amplitude about its mean steady-state position and considering only first- 
order perturbation (neglecting higher order term), nondimensional pressure and film thickness can be expressed as [11]

$$
\begin{aligned}
& \bar{p}=\bar{p}_{0}+\varepsilon_{1} e^{i \omega \tau} \bar{p}_{1}+\varepsilon_{0} \phi_{1} e^{i \omega \tau} \bar{p}_{2} \\
& \bar{h}=\bar{h}_{0}+\varepsilon_{1} e^{i \omega \tau} \cos \theta+\varepsilon_{0} \phi_{1} e^{i \omega \tau} \sin \theta
\end{aligned}
$$

On substituting $\bar{p}$ and $\bar{h}$ in (4) and equating coefficient of $\varepsilon_{0}, \varepsilon_{1} e^{i \omega \tau}$, and $\varepsilon_{0} \phi_{1} e^{i \omega \tau}$, the following set of three equations is obtained when higher-order terms are neglected:

$$
\begin{aligned}
& \frac{\partial}{\partial \theta}\left(\bar{h}_{0}{ }^{3} \frac{\partial \bar{p}_{0}}{\partial \theta}\right)+\left(\frac{D}{L}\right)^{2} \frac{\partial}{\partial \bar{z}}\left(\bar{h}_{0}{ }^{3} \frac{\partial \bar{p}_{0}}{\partial \bar{z}}\right)=\frac{\partial \bar{h}_{0}}{\partial \theta} \\
& \frac{\partial}{\partial \theta}\left(\bar{h}_{0}{ }^{3} \frac{\partial \bar{p}_{1}}{\partial \theta}\right)+\left(\frac{D}{L}\right)^{2} \frac{\partial}{\partial \bar{z}}\left(\bar{h}_{0}{ }^{3} \frac{\partial \bar{p}_{1}}{\partial \bar{z}}\right) \\
& \quad+3 \frac{\partial}{\partial \theta}\left(\bar{h}_{0}{ }^{2} \frac{\partial \bar{p}_{0}}{\partial \theta} \cos \theta\right)
\end{aligned}
$$

$\bar{p}_{0_{i, j}}=\frac{\left[\left(\bar{p}_{0_{i+1, j}}+\bar{p}_{0_{i-1, j}}\right)+C 0\left(\bar{p}_{0_{i, j+1}}+\bar{p}_{0_{i, j-1}}\right)-C 1\left(\bar{p}_{0_{i+1, j}}-\bar{p}_{0_{i-1, j}}\right)+\left(\varepsilon \sin \theta / \bar{h}_{0}^{3}\right)(\Delta \theta)^{2}\right]}{2[1+C 0]}$,

$\bar{p}_{1_{i, j}}$

$$
=\frac{\left[\left(\bar{p}_{i_{i+1, j}}+\bar{p}_{i_{i-1, j}}\right)+C 0\left(\bar{p}_{i_{i, j+1}}+\bar{p}_{i_{i, j-1}}\right)-C 1\left(\bar{p}_{i_{i+1, j}}-\bar{p}_{i_{i-1, j}}\right)-C 2\left(\bar{p}_{0_{i+1, j}}-\bar{p}_{0_{i-1, j}}\right)+C 3\left(\bar{p}_{0_{i+1, j}}-2 \bar{p}_{0_{i, j}}+2 \bar{p}_{0_{i-1, j}}\right)+C 0 \times C 3\left(\bar{p}_{0_{i, j+1}}-2 \bar{p}_{0_{i, j}}+2 \bar{p}_{0_{i, j-1}}\right)+C 4\right]}{2[1+C 0]},
$$

$\bar{p}_{2_{i, j}}$

$$
=\frac{\left[\left(\bar{p}_{2_{i+1, j}}+\bar{p}_{2_{i-1, j}}\right)+C 0\left(\bar{p}_{2_{i, j+1}}+\bar{p}_{i_{i, j-1}}\right)-C 1\left(\bar{p}_{2_{i+1, j}}-\bar{p}_{2_{i-1, j}}\right)+C 5\left(\bar{p}_{0_{i+1, j}}-\bar{p}_{0_{i-1, j}}\right)+C 6\left(\bar{p}_{0_{i+1, j}}-2 \bar{p}_{0_{i, j}}+2 \bar{p}_{0_{i-1, j}}\right)+C 0 \times C 6\left(\bar{p}_{0_{i, j+1}}-2 \bar{p}_{0_{i, j}}+2 \bar{p}_{0_{i, j-1}}\right)-C 7\right]}{2[1+C 0]},
$$

where

$$
\begin{aligned}
& C 0=\left(\frac{D}{L}\right)^{2}\left(\frac{\Delta \theta}{\Delta \bar{z}}\right)^{2} ; \\
& C 1=\frac{3 \varepsilon}{2 \bar{h}_{0}} \sin \theta(\Delta \theta) ; \\
& C 2=\frac{3}{2 \bar{h}_{2}^{2}}\left(2 \varepsilon \cos \theta+\bar{h}_{0}\right) \sin \theta(\Delta \theta), \\
& C 3=\frac{3}{\bar{h}_{0}} \cos \theta ; \\
& C 4=(\sin \theta-2 i \omega \cos \theta) \frac{(\Delta \theta)^{2}}{\bar{h}_{0}^{3}} ; \\
& C 5=\frac{3(\Delta \theta)}{2 \bar{h}_{0}^{2}}\left(\bar{h}_{0} \cos \theta-2 \varepsilon \sin ^{2} \theta\right) \\
& C 6=\frac{3}{\bar{h}_{0}} \sin \theta ; \\
& \text { C7 }=\frac{(\Delta \theta)^{2}}{\bar{h}_{0}{ }^{3}}(\cos \theta+2 i \omega \sin \theta) .
\end{aligned}
$$

Boundary conditions used for the steady-state pressure and dynamic pressure distribution are as follows:

$$
\begin{gathered}
\frac{\partial \bar{p}_{i}}{\partial \theta}=0, \quad \bar{p}_{i}=0 \text { at } \theta=\theta_{r}, \\
\bar{p}_{i}(\theta, \bar{z})=0 \quad \text { when } \theta_{s} \leq \theta \leq \theta_{e},
\end{gathered}
$$

where $\bar{p}_{i}=\bar{p}_{0}, \bar{p}_{1}, \bar{p}_{2}, \theta_{s}$ is starting angle of groove with respect to the vertical axis, $\theta_{e}$ is angle at which the groove ends with respect to the vertical axis, and $\theta_{r}$ is angle at which the film cavitates with respect to vertical axis.

Since the pressure distribution is symmetrical about the center line, only half of the bearing has been analyzed. The nondimensionalized pressure distribution equations are solved by using finite difference method (FDM). Each half of the bearing is divided into 88 and 16 elements along circumferential length and axial length, respectively. GaussSeidel method with successive overrelaxation technique satisfying boundary conditions has been used for the numerical integration.

$$
\left(p_{i, j}\right)_{\text {new }}=\left(p_{i, j}\right)_{\text {old }}+(\text { Error })_{i, j} \times \text { orf }
$$


The convergence criterion has been taken as

$$
\frac{\left|\left(\sum \bar{p}_{i, j}\right)_{N-1}-\left(\sum \bar{p}_{i, j}\right)_{N}\right|}{\left|\left(\sum \bar{p}_{i, j}\right)_{N}\right|} \leq 10^{-6} .
$$

Since the load is acting in vertical direction $\left(W_{x}\right)$, the attitude angle keeps on changing till the horizontal component becomes zero for each eccentricity ratio.

The present analysis has been carried out for the bearing with the following parameters:

$$
\begin{aligned}
& \bar{D}_{d}=0.75 ; \\
& \bar{D}_{w}=0.5 ; \\
& \bar{R}_{d}=2.0 ; \\
& \bar{R}_{w}=0.5 .
\end{aligned}
$$

The present study considers the ellipticity ratio $(\delta)=0.5$ and $L / D=1$. However, dam depth ratio and relief track ratio are not constant. At a time, one of these two variables is kept constant and the other one is varied in a certain range and the effect of the variable parameter over the performance parameter is analyzed.

Direct and cross-coupled nondimensional dynamic coefficients (stiffness and damping coefficients) are determined by separating real and imaginary parts of horizontal and vertical dynamic loads.
Horizontal and vertical components of dynamic load due to dynamic pressures $\bar{p}_{1}$ and $\bar{p}_{2}$ are given, respectively, as

$$
\begin{aligned}
& \bar{W}_{z 1}=\int_{\theta_{s}}^{\theta_{e}} \int_{0}^{1} \bar{p}_{1} \cos \theta d \theta d \bar{z} ; \\
& \bar{W}_{z 2}=\int_{\theta_{s}}^{\theta_{e}} \int_{0}^{1} \bar{p}_{2} \cos \theta d \theta d \bar{z} ; \\
& \bar{W}_{x 1}=\int_{\theta_{s}}^{\theta_{e}} \int_{0}^{1} \bar{p}_{1} \sin \theta d \theta d \bar{z} ; \\
& \bar{W}_{x 2}=\int_{\theta_{s}}^{\theta_{e}} \int_{0}^{1} \bar{p}_{2} \cos \theta d \theta d \bar{z} ; \\
& \bar{K}_{x x}=-\operatorname{Re}\left(\bar{W}_{x 1}\right) ; \\
& \bar{K}_{x z}=-\operatorname{Re}\left(\bar{W}_{x 2}\right) \text {, } \\
& \bar{K}_{z x}=-\operatorname{Re}\left(\bar{W}_{z 1}\right) ; \\
& \bar{K}_{z z}=-\operatorname{Re}\left(\bar{W}_{z 2}\right) \\
& \bar{C}_{x x}=-\operatorname{Im}\left(\bar{W}_{x 1}\right) ; \\
& \bar{C}_{x z}=-\operatorname{Im}\left(\bar{W}_{x 2}\right) \text {, } \\
& \bar{C}_{z x}=-\operatorname{Im}\left(\bar{W}_{z 1}\right) ; \\
& \bar{C}_{z z}=-\operatorname{Im}\left(\bar{W}_{z 2}\right) \text {. }
\end{aligned}
$$

Nondimensional mass parameter, flow coefficient, friction variable, and Sommerfeld number are given as

$$
\begin{aligned}
& \bar{M}=\frac{m c \omega^{2}}{W}=\frac{K_{0}}{\omega^{2}} \\
& \quad \text { where, } K_{0}=\frac{\left(\bar{K}_{X X} \bar{C}_{Z Z}+\bar{K}_{Z Z} \bar{C}_{X X}\right)-\left(\bar{K}_{X Z} \bar{C}_{Z X}+\bar{K}_{Z X} \bar{C}_{X Z}\right)}{\bar{C}_{X X}+\bar{C}_{Z Z}}, \omega^{2}=\frac{\left(\bar{K}_{X X}-K_{0}\right)\left(\bar{K}_{Z Z}-K_{0}\right)-\bar{K}_{X Z} \bar{C}_{Z X}}{\bar{C}_{X X} \bar{C}_{Z Z}+\bar{C}_{X Z} \bar{C}_{Z X}} \\
& \bar{q}_{z}=\frac{1}{2}\left(\frac{D}{L}\right)^{2} \int_{0}^{2 \pi} \bar{h}_{0}^{3} \frac{\partial \bar{p}_{0}}{\partial \bar{z}} d \theta ; \\
& \bar{\mu}=\mu\left(\frac{R}{C}\right)=\frac{\int_{0}^{2 \pi}\left(3 \bar{h}\left(\partial \bar{p}_{0} / \partial \bar{z}\right)+1 / \bar{h}_{0}\right) d \theta}{6 \bar{W}} \\
& S=\frac{1}{6 \pi \bar{W}} .
\end{aligned}
$$

The nondimensional film thickness in the entire rectangular pressure dam region is given as

$$
\bar{h}=\bar{h}_{0}+\bar{D}_{d}
$$

Similarly, for the relief track region,

$$
\bar{h}=\bar{h}_{0}+\bar{R}_{d}
$$

where $\bar{h}_{0}=1+\varepsilon_{i} \cos (\theta-\phi) ; i=1,2$, and 3 for lobes 1,2 , and 3 , respectively. 


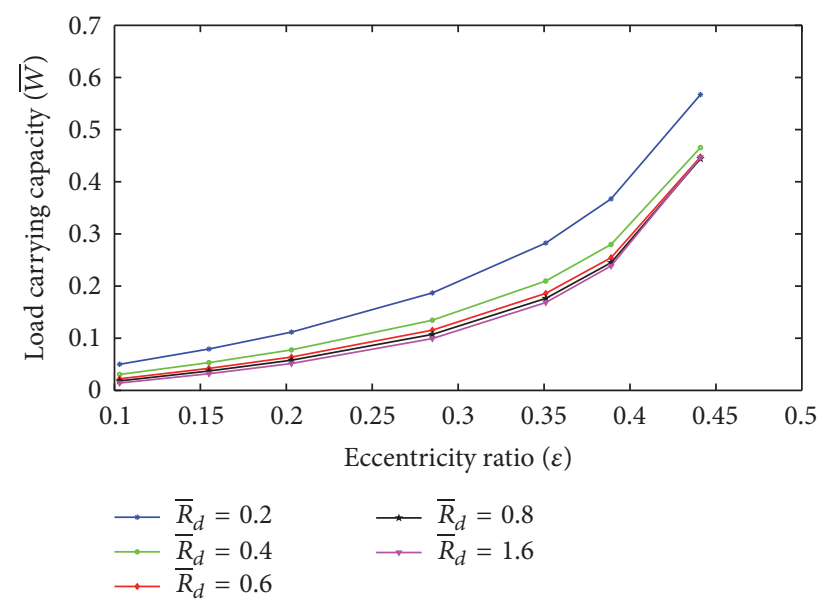

FIGURE 3: Effect of relief track depth ratio on load carrying capacity.

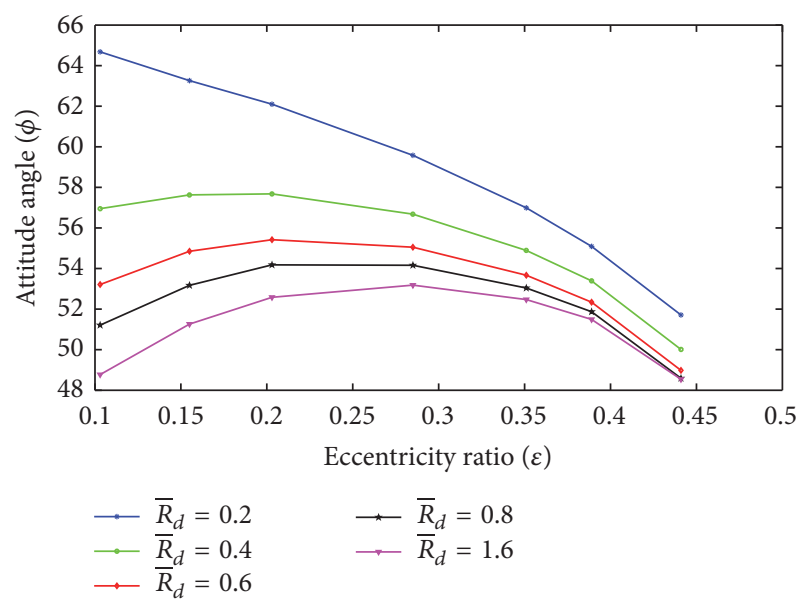

FIGURE 4: Effect of relief track depth ratio on attitude angle.

Since $\bar{M}$ is closely related to the journal rotational speed and journal mass is normally constant, it is more convenient to define a speed parameter $\bar{\omega}_{S}$ which is equal to square root of $\bar{M}$.

\section{Results and Discussion}

Various performance parameters have been plotted against eccentricity ratio $(\varepsilon)$ for different pressure dam depth ratio $\left(\bar{D}_{d}\right)$ and relief track depth ratio $\left(\bar{R}_{d}\right)$. In the first section, the effect of the relief track depth ratio has been shown by keeping other parameters constant $\left(\bar{D}_{d}=0.75 ; \bar{D}_{w}=0.5 ; \bar{R}_{w}=\right.$ $0.75)$. Relief track depth ratio has been taken as $\left(\bar{R}_{d}=0.2,0.4\right.$, $0.6,0.8$, and 1.6). In the second section, the effect of the pressure dam depth ratio has been shown by keeping other parameters constant $\left(\bar{R}_{d}=1.6 ; \bar{D}_{w}=0.5 ; \bar{R}_{w}=0.75\right)$. Dam depth ratio has been taken as $\left(\bar{D}_{d}=0.2,0.3,0.8\right.$, and 1.4$)$.

Throughout the study, $L / D$ ratio has been taken as 1.0 and ellipticity ratio $(\delta)$ has been taken as 0.5 .

Figures 3-7 show the effect of relief track depth ratio on the steady-state parameters. Load carrying capacity decreases

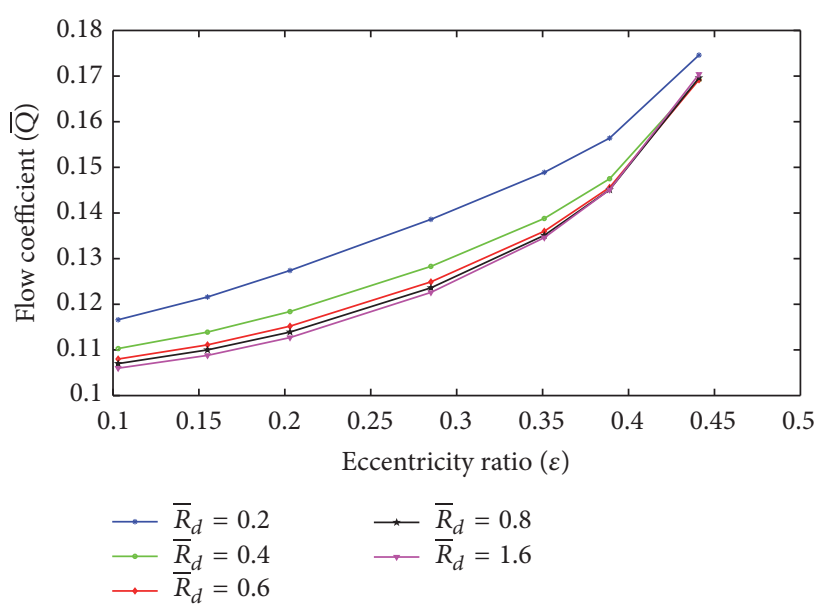

FIGURE 5: Effect of relief track depth ratio on flow coefficient.

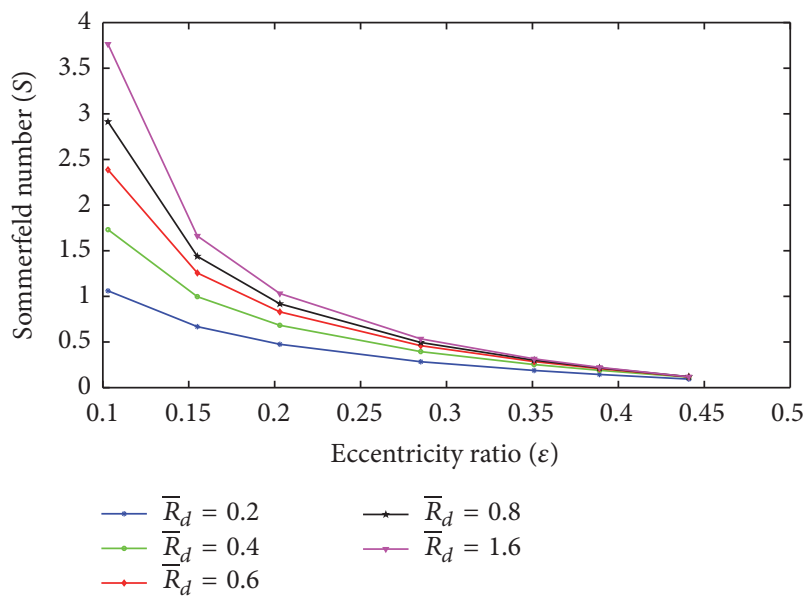

FIgURE 6: Effect of relief track depth ratio on Sommerfeld number.

with increase in $\bar{R}_{d}$. As shown in Figure 3, the variation in relief track depth ratio between 0.2 and 0.6 has a significant effect on load carrying capacity but as the relief track depth ratio goes beyond 0.6 , the variation in load carrying capacity becomes very minor. Presence of relief track increases the film thickness and hence pressure at the bottom of the shaft decreases; consequently the load carrying capacity also decreases.

Attitude angle of bearing decreases with increase in relief track depth ratio as seen in Figure 4. For higher value of relief track depth ratio, the attitude angle first increases with eccentricity ratio and then decreases.

The behavior of flow coefficient is more or less similar to the load carrying capacity. Figure 5 shows that flow coefficient also decreases with increase in relief track depth ratio and for a given relief track depth ratio flow coefficient increases with increase in eccentricity ratio.

The Sommerfeld number and friction variable behave in similar manner for different relief track depth ratio as shown in Figures 6 and 7, respectively. In both cases, as the relief track ratio increases, the Sommerfeld number and friction variable also increase, but, for a given relief track depth ratio, 


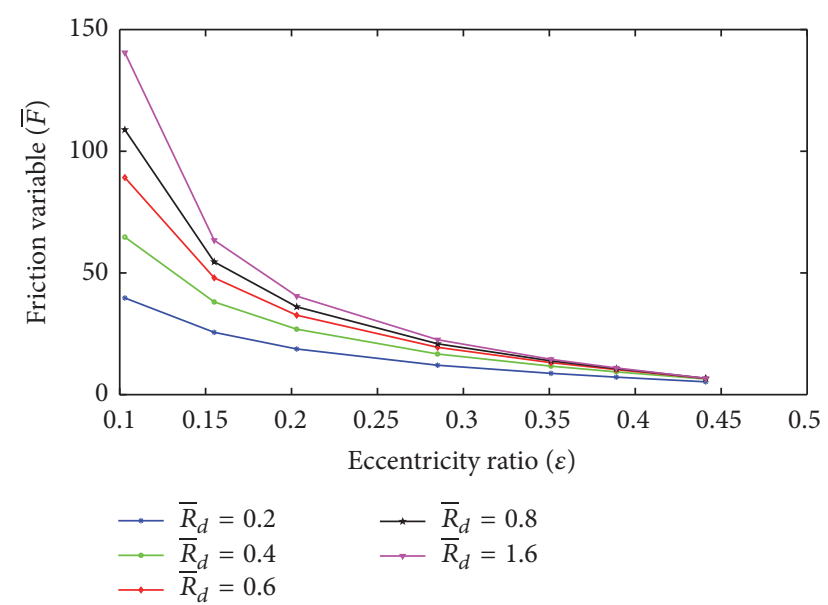

FIGURE 7: Effect of relief track depth ratio on friction variable.

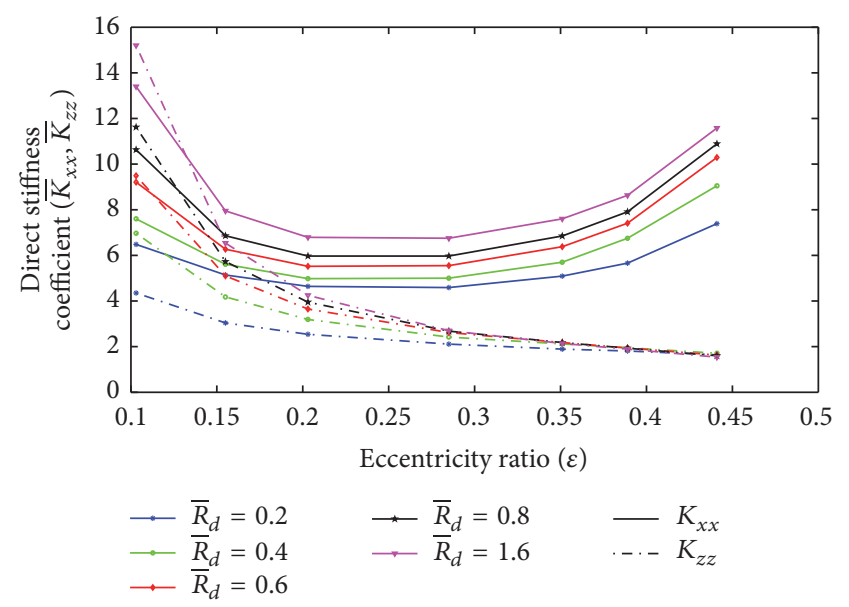

Figure 8: Effect of relief track depth ratio on direct stiffness coefficient.

these keep on decreasing with increase in eccentricity ratio. For all relief track depth ratio, Sommerfeld number and flow coefficient converge at eccentricity ratio of 0.441 .

Figures 8-11 show the variation in dynamic coefficients with eccentricity ratio for different relief track depth ratio. Figure 8 depicts that $\bar{K}_{x x}$ and $\bar{K}_{z z}$ increase with increase in $\bar{R}_{d}$ but with increase in eccentricity ratio for given $\bar{R}_{d}$, $\bar{K}_{x x}$ first decreases and then increases, whereas $\bar{K}_{z z}$ keeps on decreasing. For all the value of $\bar{R}_{d}, \bar{K}_{z z}$ is found to be converging at an eccentricity ratio of 0.441 .

Figure 9 shows the variation in cross-coupled stiffness coefficient with eccentricity ratio for different value of $\bar{R}_{d}$. $\bar{K}_{x z}$ increases with increase in $\bar{R}_{d}$, whereas $\bar{K}_{z x}$ decreases with increase in $\bar{R}_{d}$. For given $\bar{R}_{d}$, there is a decrease in $\bar{K}_{x z}$ but an increase in $\bar{K}_{z x}$ can be seen.

Figures 8 and 9 also depict that both direct and crosscoupled stiffness coefficients increase with increase in relief track depth ratio. As a result of this, the bearing gets more and more stiff.

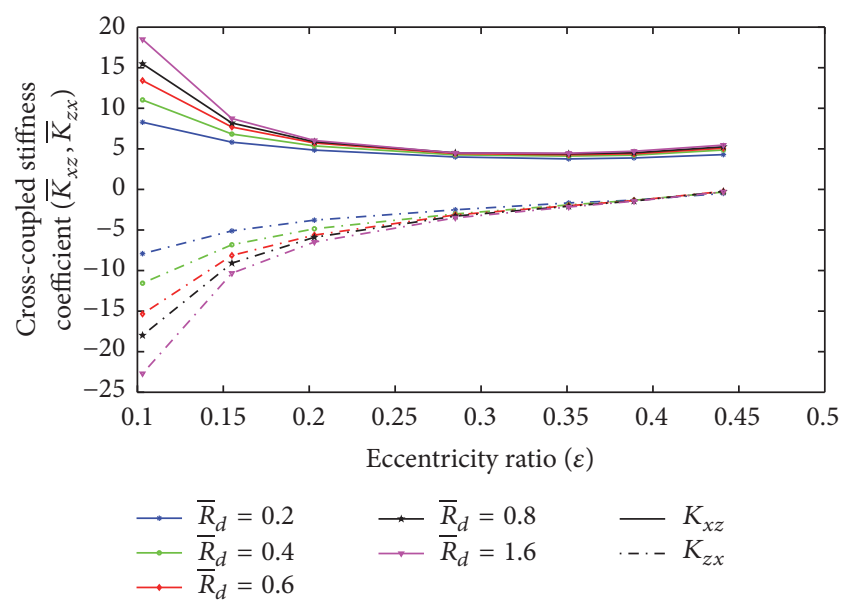

FIGURE 9: Effect of relief track depth ratio on cross-coupled stiffness coefficient.

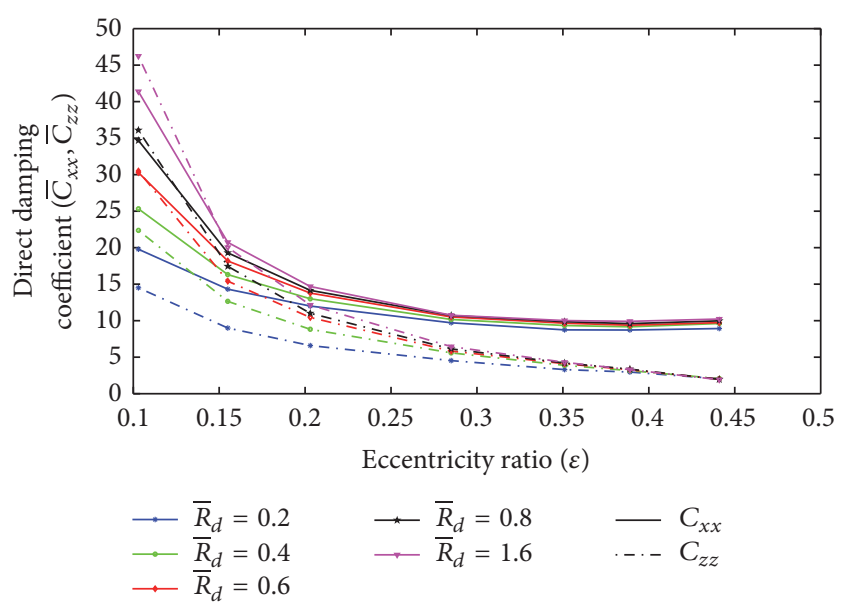

FIGURE 10: Effect of relief track depth ratio on direct damping coefficient.

The behavior of direct damping coefficient and crosscoupled damping coefficient can be seen from Figures 10 and 11. Both direct and cross-coupled damping coefficients increase with increase in relief track depth ratio. The direct and cross-coupled damping coefficients converge with eccentricity ratio for all the given relief track depth ratios and these become almost equal for eccentricity ratio of 0.441 .

Figure 12 shows the effect on mass parameter which determines the stability of the bearing. As the relief track depth ratio increases, the mass parameter increases and hence the stability also increases. Beyond eccentricity ratio of 0.4 , mass parameter shows negative value for all relief track depth ratio. Negative value of mass parameter shows that the bearing is stable for all speeds [12]. The bearing becomes infinitely stable beyond $\varepsilon=0.35$ for $\bar{R}_{d}=1.6$.

Figure 13 shows that, with increase in relief track depth ratio, the whirling tendency of shaft reduces. This reduction in whirling tendency improves the stability of the shaft. For the relief track depth ratio up to 0.8 , the plot shows the whirl ratio up to 0.389 eccentricity ratio but for $\bar{R}_{d}=1.6$ it shows 


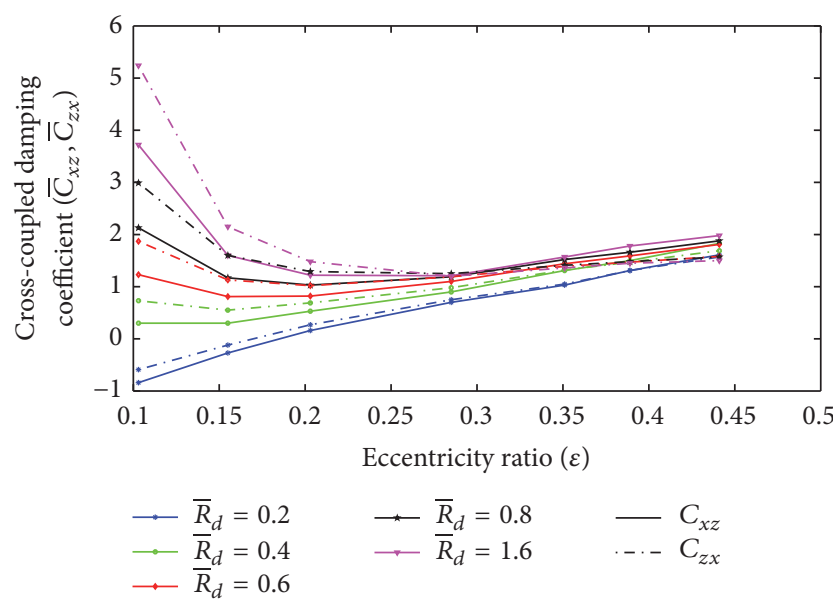

Figure 11: Effect of relief track depth ratio on cross-coupled damping coefficient.

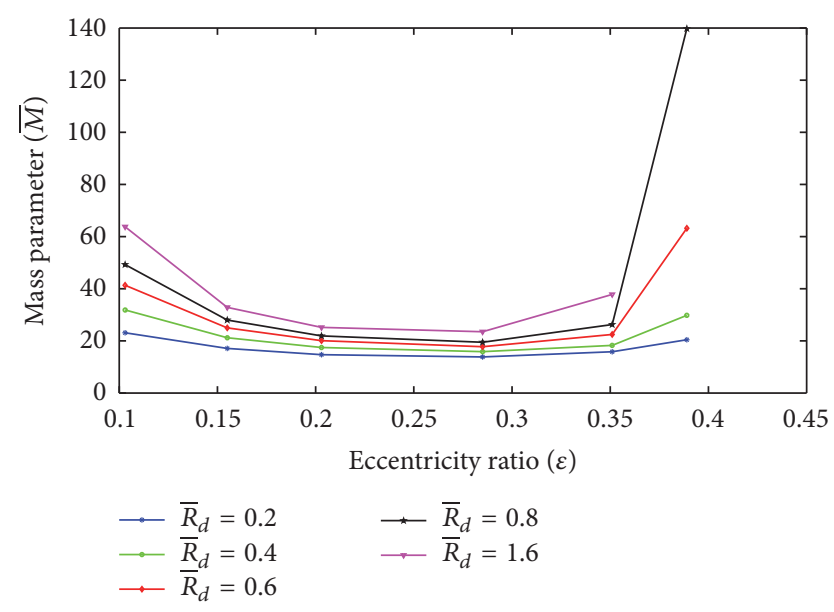

FIGURE 12: Effect of relief track depth ratio on mass parameter.

only up to 0.351 eccentricity ratio. This is because of the reason that in case of $\bar{R}_{d}=1.6$ the bearing goes to the infinite stability zone after $\varepsilon=0.351$, whereas in case of $\bar{R}_{d}=0.2$ to 0.8 bearing attains the infinite stability after $\varepsilon=0.389$.

The dam depth ratio shows different behavior compared to the relief track depth ratio. Pressure dam is provided in the upper half of the bearing by providing a step. When the lubricating oil passes through this passage due to step provided, a high pressure zone is created which pushes the bearing downward. This high pressure results in increase in apparent load on the bearing. Consequently, the whirling tendency of shaft is reduced and bearing shows better stability even at low load and high speed condition.

Figure 14 shows that there is no significant change in load carrying capacity with dam depth ratio. In general, load carrying capacity is observed to increase, with increase in eccentricity ratio for all the value of dam depth ratio.

With increase in dam depth ratio, attitude angle increases for a given eccentricity ratio. It can also be observed from Figure 15 that, for a given dam depth ratio, as the eccentricity ratio increases, the attitude angle first increases and attains its

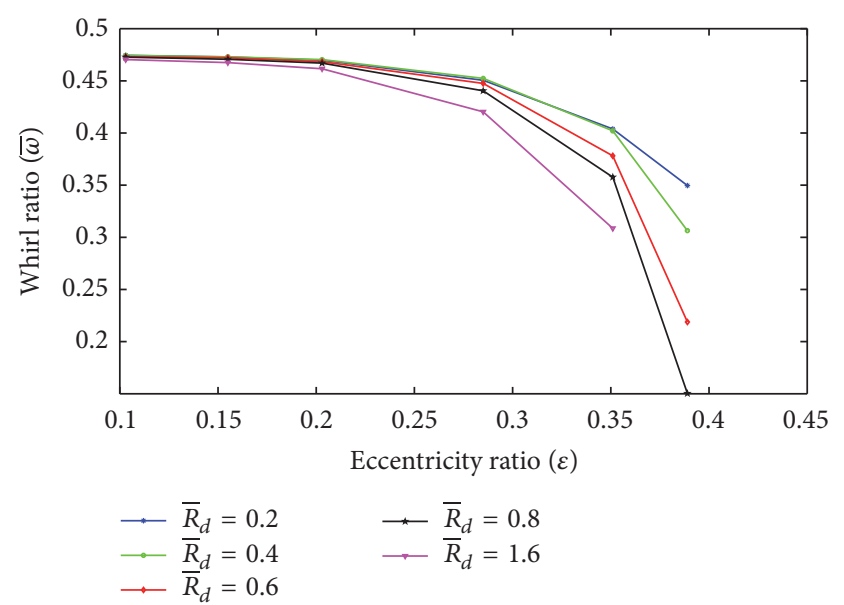

FIGURE 13: Effect of relief track depth ratio on whirl ratio.

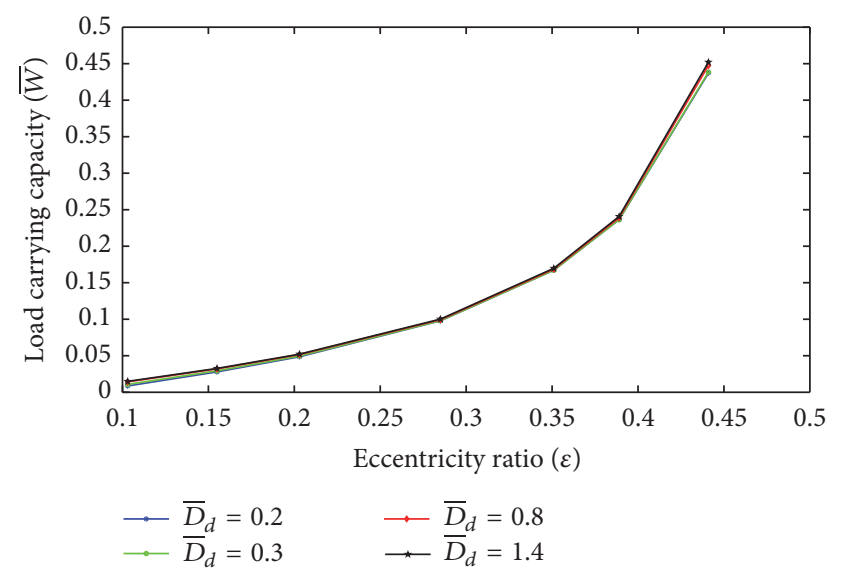

FIGURE 14: Effect of dam depth ratio on load carrying capacity.

maximum value near about 0.289 eccentricity ratio and then decreases.

The flow coefficient decreases as the dam depth ratio increases for a given eccentricity ratio; however, flow coefficient increases with increase in eccentricity ratio for a given dam depth ratio, as seen in Figure 16. Keeping the eccentricity ratio constant, the dam depth ratio shows significant decrease in flow coefficient up to $\bar{R}_{d}=0.8$, but beyond that the change in flow coefficient becomes negligible.

Sommerfeld number and friction variable show the same behavior with dam depth ratio. As shown in Figures 17 and 18 , the Sommerfeld number and friction variable decrease with increase in dam depth ratio. The effect of dam depth ratio is dominant for lower eccentricity ratio but, beyond the eccentricity ratio of 0.2 , Sommerfeld number and friction variable become almost constant for all the value of dam depth ratio.

Figures 19-22 show the variation in direct and crosscoupled stiffness and damping coefficients. For the lower eccentricity ratios, reduction in stiffness and damping coefficient is shown with increase in dam depth ratio. But, for any given eccentricity ratio beyond $0.2, \bar{K}_{x x}$ becomes more 


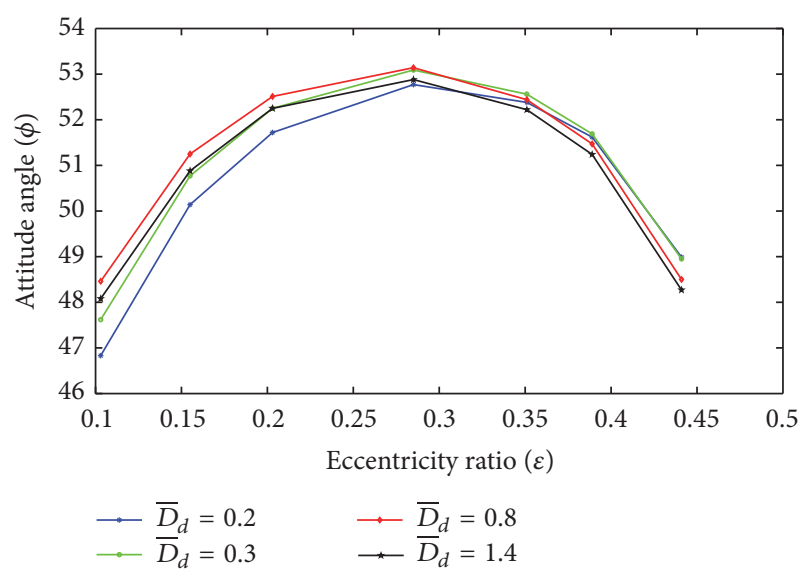

FIGURE 15: Effect of dam depth ratio on attitude angle.

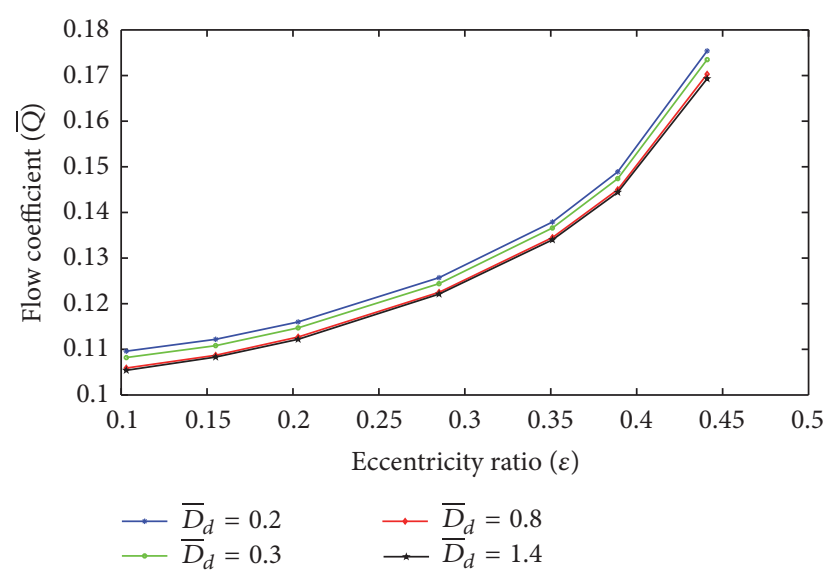

Figure 16: Effect of dam depth ratio on flow coefficient.

or less the same for all the values of dam depth ratio as seen in Figure 19. For different dam depth ratio, both $\bar{K}_{x x}$ and $\bar{K}_{z z}$ converge separately at higher eccentricity ratio. Figure 19 also shows that $\bar{K}_{z z}$ has higher value than $\bar{K}_{x x}$ for a given dam depth ratio and eccentricity ratio but as the eccentricity ratio increases, $\bar{K}_{x x}$ becomes higher than $\bar{K}_{z z}$.

Figure 20 shows that $\bar{K}_{x z}$ decreases with increase in dam depth ratio for a given eccentricity ratio but as the eccentricity ratio increases both $\bar{K}_{x z}$ and $\bar{K}_{z x}$ become constant separately for any given dam depth ratio. For higher eccentricity ratios, $\bar{K}_{x z}$ becomes the same for all the dam depth ratios and the same can be seen for $\bar{K}_{z x}$.

In case of direct damping coefficient, as the dam depth ratio increases, both $\bar{C}_{x x}$ and $\bar{C}_{z z}$ decrease. For any given value of dam depth ratio and eccentricity ratio less than 0.2 , $\bar{C}_{z z}$ is higher than $\bar{C}_{x x}$, but, for the same dam depth ratio and eccentricity ratio more than $0.2, \bar{C}_{x x}$ has higher value than $\bar{C}_{z z}$. At $\varepsilon=0.2$, both $\bar{C}_{x x}$ and $\bar{C}_{z z}$ have the same value for given dam depth ratio as seen in Figure 21. For all dam depth ratios, $\bar{C}_{x x}$ converges at $\varepsilon=0.441$ and the similar situation has been observed for $\bar{C}_{z z}$.

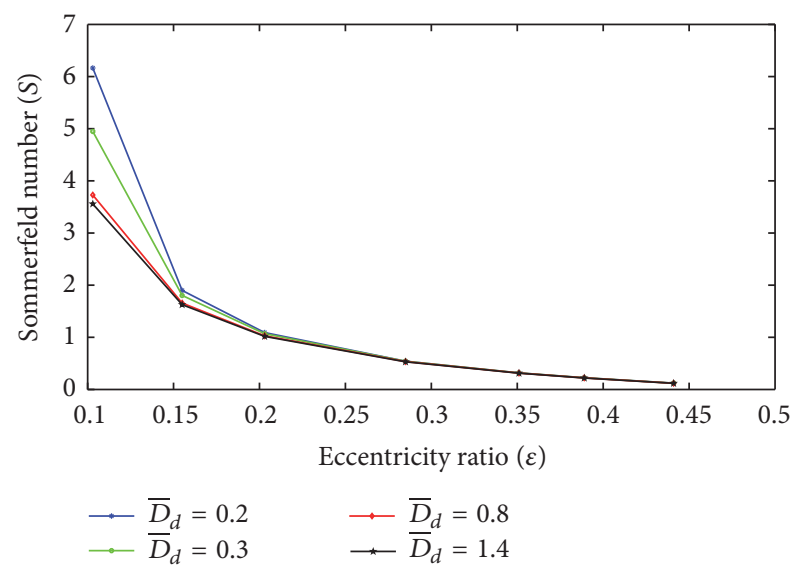

FIGURE 17: Effect of dam depth ratio on Sommerfeld number.

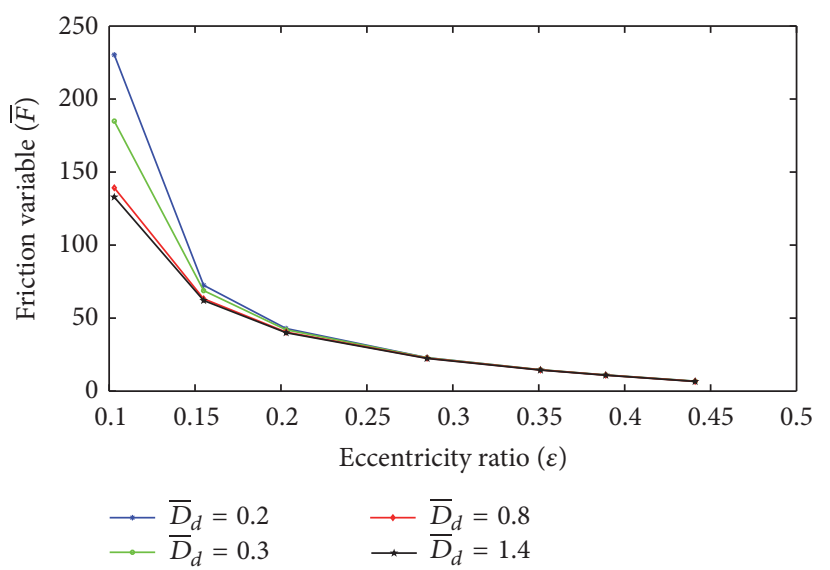

Figure 18: Effect of dam depth ratio on friction variable.

Figure 22 shows that cross-coupled damping coefficient decreases as the dam depth ratio of three-lobe pressure dam bearing increases. For a given dam depth ratio, the difference between $\bar{C}_{x z}$ and $\bar{C}_{z x}$ is very less. For the lower eccentricity ratio (up to 0.25), $\bar{C}_{z x}$ is higher than $\bar{C}_{x z}$, but, for higher eccentricity ratio (beyond 0.25), $\bar{C}_{x z}$ exceeds $\bar{C}_{z x}$. Lower dam depth ratio shows more influence on $\bar{C}_{x z}$ and $\bar{C}_{z x}$ than the higher dam depth ratio.

For the lower eccentricity ratio (up to 0.25), mass parameter decreases with increase in dam depth ratio but as the eccentricity ratio increases and goes beyond 0.25 , the pattern changes and the bearing with higher dam depth ratio shows higher stability as the mass parameter increases as seen in Figure 23. Bearing becomes infinitely stable beyond eccentricity ratio of 0.35 for dam depth ratio of 0.8 and 1.4 , whereas bearing attains infinite stability after eccentricity ratio of 0.4 in case of dam depth ratio of 0.2 and 0.3 .

Figure 24 shows that, with increase in dam depth ratio, the whirling tendency of shaft reduces. This reduction in whirling tendency improves the stability of the journal. For the dam depth ratio of 0.2 and 0.4 , the plot shows the whirl ratio up to 0.389 eccentricity ratio, but, for $\bar{D}_{d}=0.8$ and 1.4, it shows only up to 0.351 eccentricity ratio. This is because of 


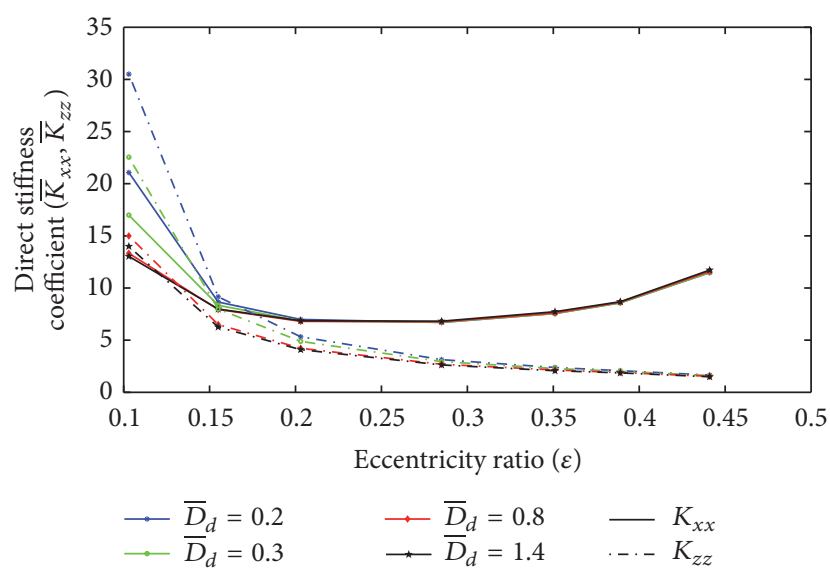

FIGURE 19: Effect of dam depth ratio on direct stiffness coefficient.

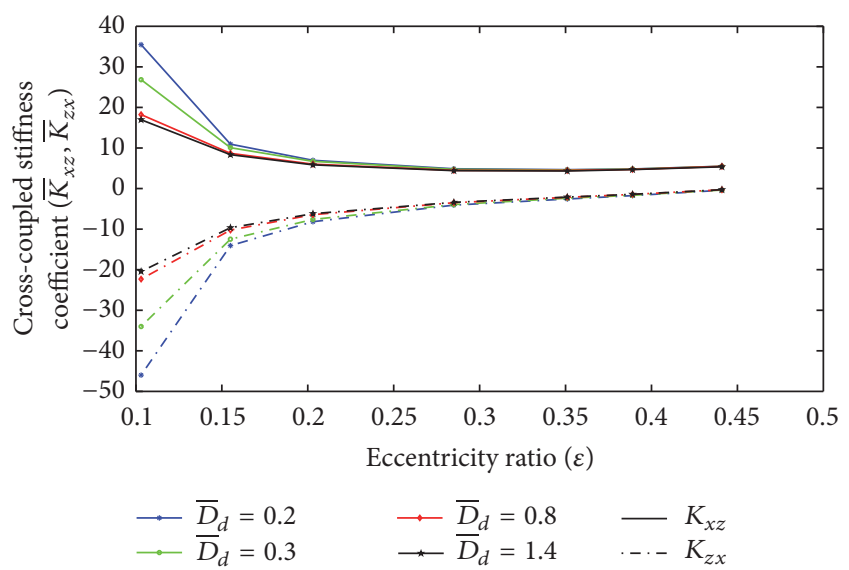

Figure 20: Effect of dam depth ratio on cross-coupled stiffness coefficient.

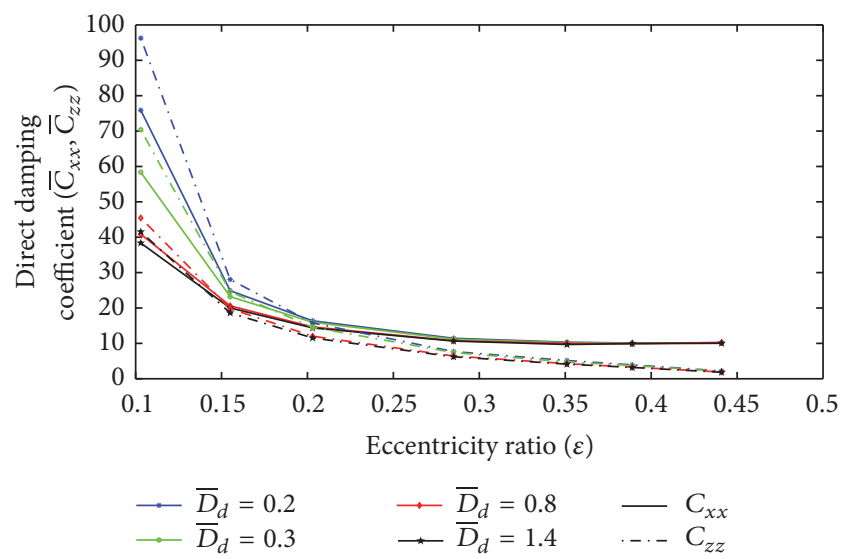

FIGURE 21: Effect of dam depth ratio on direct damping coefficient.

the reason that in case of $\bar{D}_{d}=0.8$ and 1.4 the bearing goes to the infinite stability zone after $\varepsilon=0.351$, whereas in case of $\bar{R}_{d}=0.2$ to 0.3 bearing attains the infinite stability after $\varepsilon=0.389$.

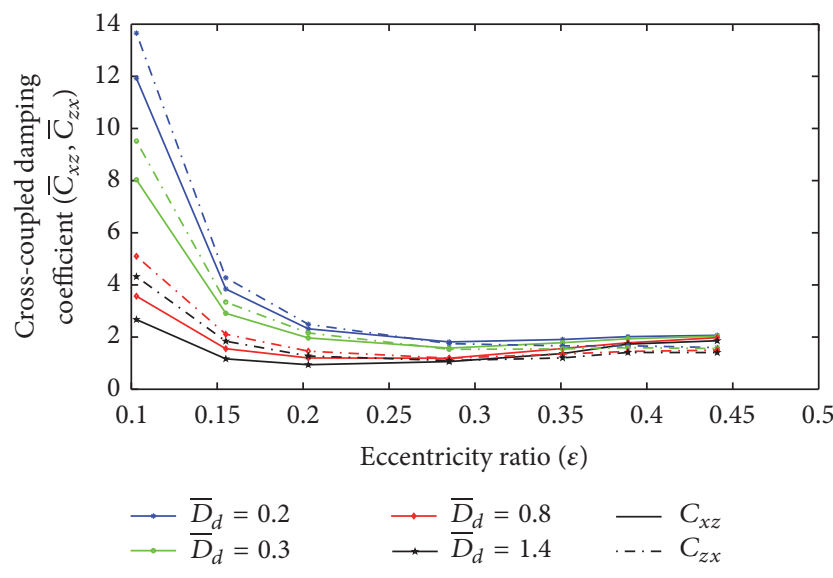

FIGURE 22: Effect of dam depth ratio on cross-coupled damping coefficient.

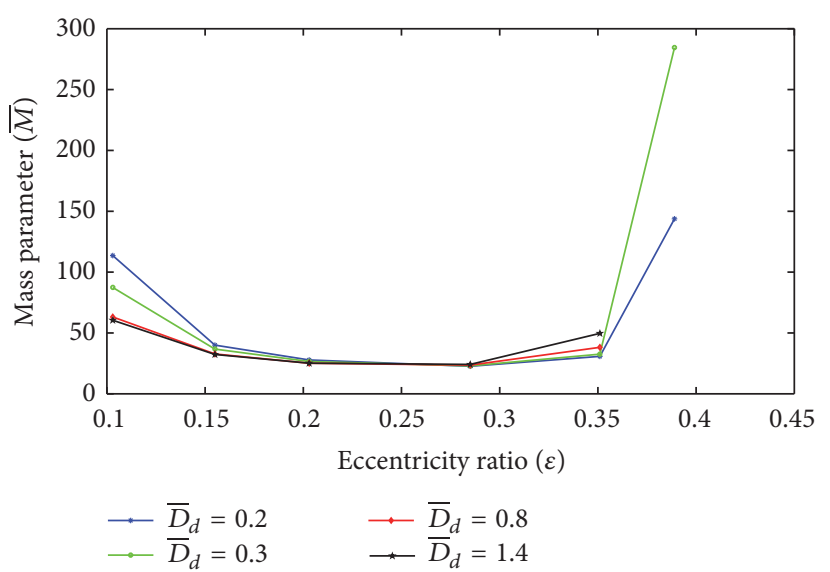

Figure 23: Effect of dam depth ratio on mass parameter.

\section{Conclusion}

From the study carried out here, the following conclusions are made:

(1) As the relief track depth ratio increases, the stiffness of the bearing increases. As a result of that, the threshold speed and zone of infinite stability increase.

(2) With increase in relief track ratio, load carrying capacity, attitude angle, and flow coefficient decrease, whereas Sommerfeld number and friction variable increase.

(3) Relief track ratio between 0.2 and 0.6 has much significant effect on load carrying capacity and flow coefficient for a given eccentricity ratio but, for higher relief track ratio, this effect becomes insignificant.

(4) For a given eccentricity ratio, the effect of pressure dam depth ratio on load carrying capacity is almost negligible.

(5) Pressure dam depth ratio does not have significant effect on performance parameters of journal bearing if eccentricity ratio goes beyond 0.2 . 


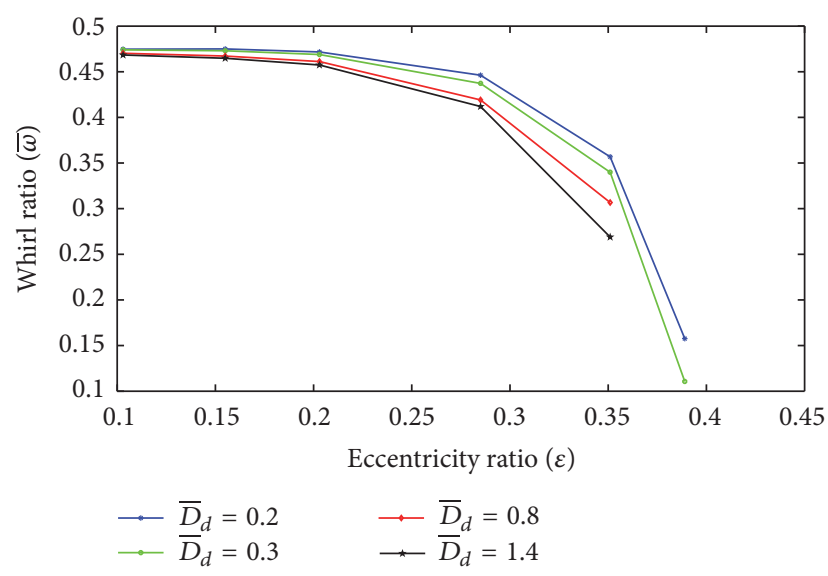

FIgURE 24: Effect of dam depth ratio on whirl ratio.

(6) The incorporation of pressure dam and relief track in a three-lobe journal bearing increases the stability and threshold speed but the depth of pressure dam and relief rack has to be set very carefully because it has great significance on overall performance.

\section{Nomenclature}

C:

Radial clearance, $\mathrm{m}$

$C_{m}:$

Minimum film thickness for a

centered shaft, $\mathrm{m}$

$C_{x x}, C_{x z}, C_{z x}, C_{z z}:$ Oil-film damping coefficients, Ns/m

$\bar{C}_{x x}, \bar{C}_{x z}, \bar{C}_{z x}, \bar{C}_{z z}$ : Nondimensional oil-film damping

coefficients $\bar{C}_{x x}=C_{x x}(\omega C / W)$

e:

Eccentricity, $\mathrm{m}$

$\varepsilon: \quad$ Eccentricity ratio $\varepsilon=e / C$

$e_{1}, e_{2}, e_{3}: \quad$ Eccentricity for each lobe, $\mathrm{m}$

$h: \quad$ Oil-film thickness, $m$

$\bar{h}: \quad \quad$ Nondimensional oil-film thickness

$\bar{h}=h / C$

$K_{x x}, K_{x z}, K_{z x}, K_{z z}:$ Oil-film stiffness coefficients, N/m

$\bar{K}_{x x}, \bar{K}_{x z}, \bar{K}_{z x}, \bar{K}_{z z}$ : Nondimensional oil-film stiffness

coefficients $\bar{K}_{x x}=K_{x x}(C / W)$

$L:$

Bearing length, $m$

$D_{d}:$

$\bar{D}_{d}$ :

$D_{w}$ :

$\bar{D}_{w}$ :

$R_{d}:$

$\bar{R}_{d}$ :

$R_{w}$ :

$\bar{R}_{w}$ :

$m:$

$\omega:$
$\bar{M}: \quad$ Nondimensional mass parameter

$\bar{M}=m C \omega^{2} / W$

$N$ : $\quad$ Speed of the journal, rps

$D: \quad$ Diameter of journal, $\mathrm{m}$

$p$ : $\quad$ Load per unit bearing area $p=(W / L D)$, $\mathrm{N} / \mathrm{m}^{2}$

$\bar{p}: \quad$ Nondimensional film pressure

$\bar{p}=p C^{2} / 6 \eta U R$

$R: \quad$ Bearing radius, $\mathrm{m}$

$U: \quad$ Sliding speed, $\mathrm{m} / \mathrm{s}$

$\eta: \quad$ Coefficient of viscosity, $\mathrm{Pa}-\mathrm{s}$

$\phi$ : $\quad$ Beating attitude angle, rad

$S: \quad$ Sommerfeld number $S=\eta N / p(R / C)^{2}$

$\bar{\mu}$ : Nondimensional friction variable

$\bar{\mu}=\mu(R / C)$

$W: \quad$ Load carrying capacity, $\mathrm{N}$

$\bar{W}: \quad$ Nondimensional load carrying capacity $\bar{W}=W C^{2} / 6 \eta U R^{2} L$

$\bar{Q}: \quad$ Nondimensional flow coefficient

$\bar{p}_{1}, \bar{p}_{2}$ : Nondimensional perturbed pressure

$\delta: \quad$ Ellipticity ratio $\delta=d / C$

$d$ : $\quad$ Distance of lobe center from bearing geometry center, $\mathrm{m}$

$t: \quad$ time, $\mathrm{s}$

$\tau: \quad$ Nondimensional time $\tau=\omega_{p} t$

$\omega_{p}: \quad$ Angular velocity of whirl, $\mathrm{rad} / \mathrm{s}$

$\bar{\omega}_{j}: \quad$ Nondimensional speed parameter

$W_{x}$ : Vertical component of the resultant load, $\mathrm{N}$

$W_{z}$ : Horizontal component of the resultant load, N.

\section{Competing Interests}

The authors declare that they have no competing interests.

\section{References}

[1] J. C. Nicholas and P. E. Allaire, "Analysis of step journal bearings-finite length, stability," ASLE Transactions, vol. 23, no. 2, pp. 197-207, 1980.

[2] J. C. Nicholas, P. E. Allaire, and D. W. Lewis, "Stiffness and damping coefficients for finite length step journal bearings," ASLE Transactions, vol. 23, no. 4, pp. 353-362, 1980.

[3] A. Singh and B. K. Gupta, "Static and dynamic properties of oil films in displaced centres elliptical bearings," Proceedings of the Institution of Mechanical Engineers, Part C: Journal of Mechanical Engineering Science, vol. 197, no. 3, pp. 159-165, 1983.

[4] N. P. Mehta and S. S. Rattan, "Stability analysis of three-lobe bearings with pressure dams," Wear, vol. 167, no. 2, pp. 181-185, 1993.

[5] J. W. Lund and K. K. Thomson, "A calculation method and data for the dynamic coefficient of oil-lubricated journal bearings," in Proceedings of the ASME Design and Engineering Conference, pp. 1-28, New York, NY, USA, 1978.

[6] S. C. Soni, R. Sinhasan, and D. V. Singh, "Performance characteristics of noncircular bearings in laminar and turbulent flow regimes," ASLE Transactions, vol. 24, no. 1, pp. 29-41, 1981. 
[7] A. Kumar, R. Sinhasan, and D. V. Singh, "Performance characteristics of two-lobe hydrodynamic journal bearings," Journal of Lubrication Technology, vol. 102, no. 4, pp. 425-429, 1980.

[8] N. P. Mehta, "Static and dynamic characteristics of orthogonally-displaced pressure dam bearings," Tribology Transactions, vol. 36, no. 2, pp. 201-206, 1993.

[9] N. P. Mehta and A. Singh, "Stability analysis of finite offsethalves pressure dam bearing," Journal of Tribology, vol. 108, no. 2, pp. 270-274, 1986.

[10] S. Sharma and S. S. Ratan, "Micropolar lubricant effects on the performance of a two-lobe bearing with pressure dam," International Journal of Engineering Science and Technology, vol. 2, no. 10, pp. 5637-5646, 2010.

[11] S. Das, S. K. Guha, and A. K. Chattopadhyay, "Linear stability analysis of hydrodynamic journal bearings under micropolar lubrication," Tribology International, vol. 38, no. 5, pp. 500-507, 2005.

[12] D. F. Li, K. C. Choy, and P. E. Allaire, "Stability and transient characteristics of four multilobe journal bearing configurations," Journal of lubrication technology, vol. 102, no. 3, pp. 291299, 1980. 


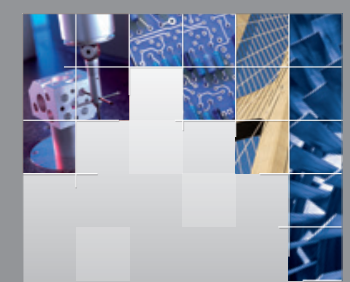

\section{Enfincering}
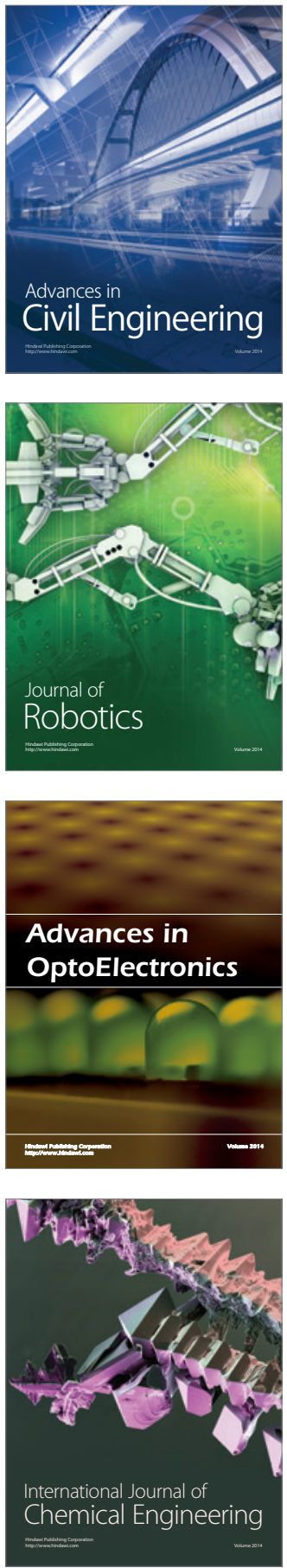

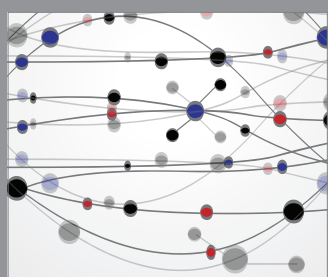

The Scientific World Journal

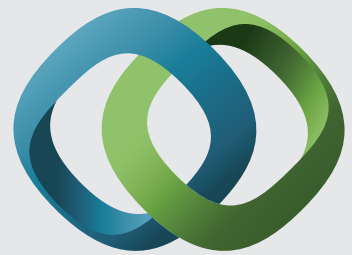

\section{Hindawi}

Submit your manuscripts at

https://www.hindawi.com
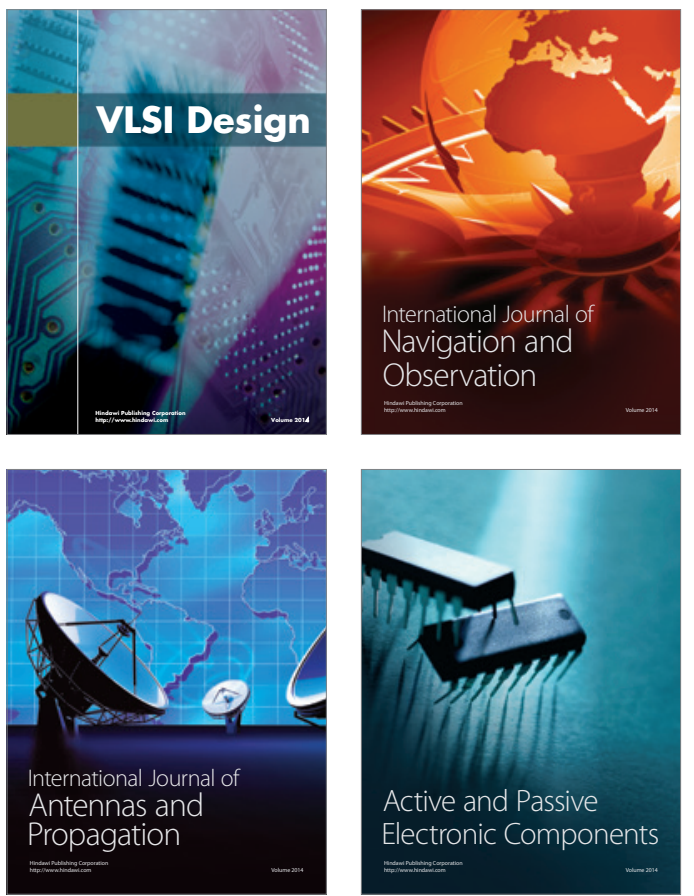
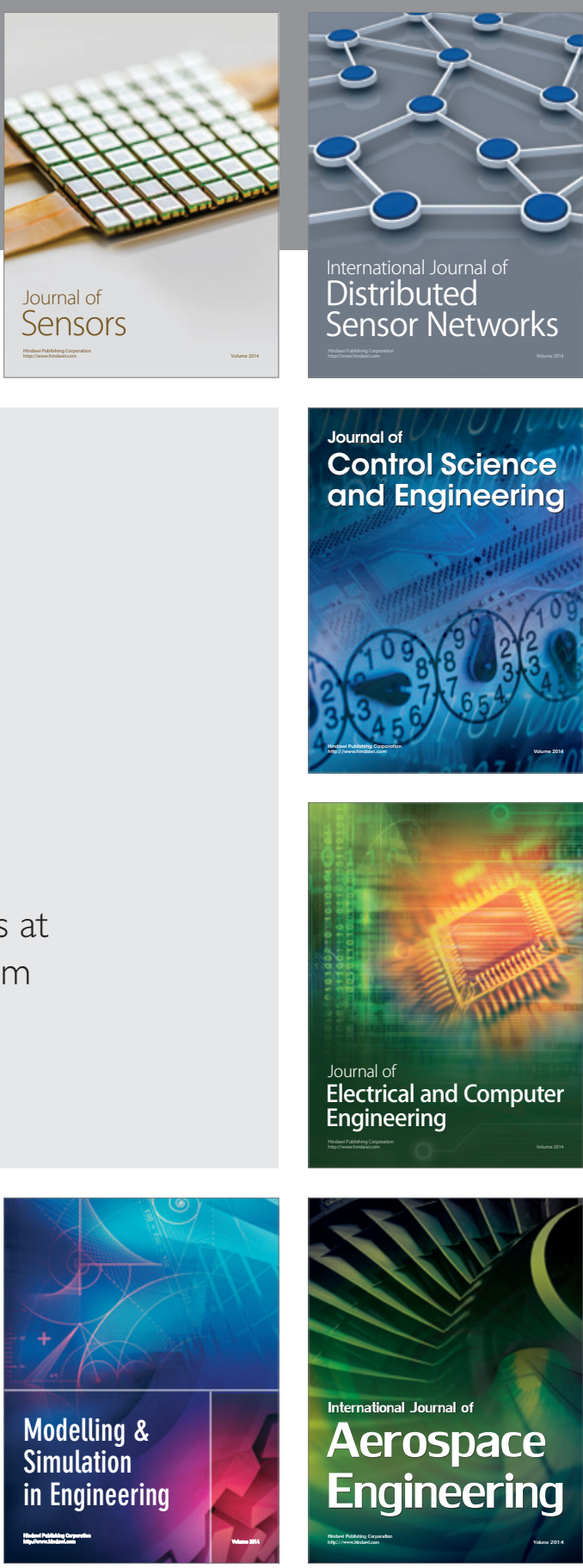

International Journal of

Distributed

Sensor Networks

$-$

Joumal of

Control Science

and Engineering
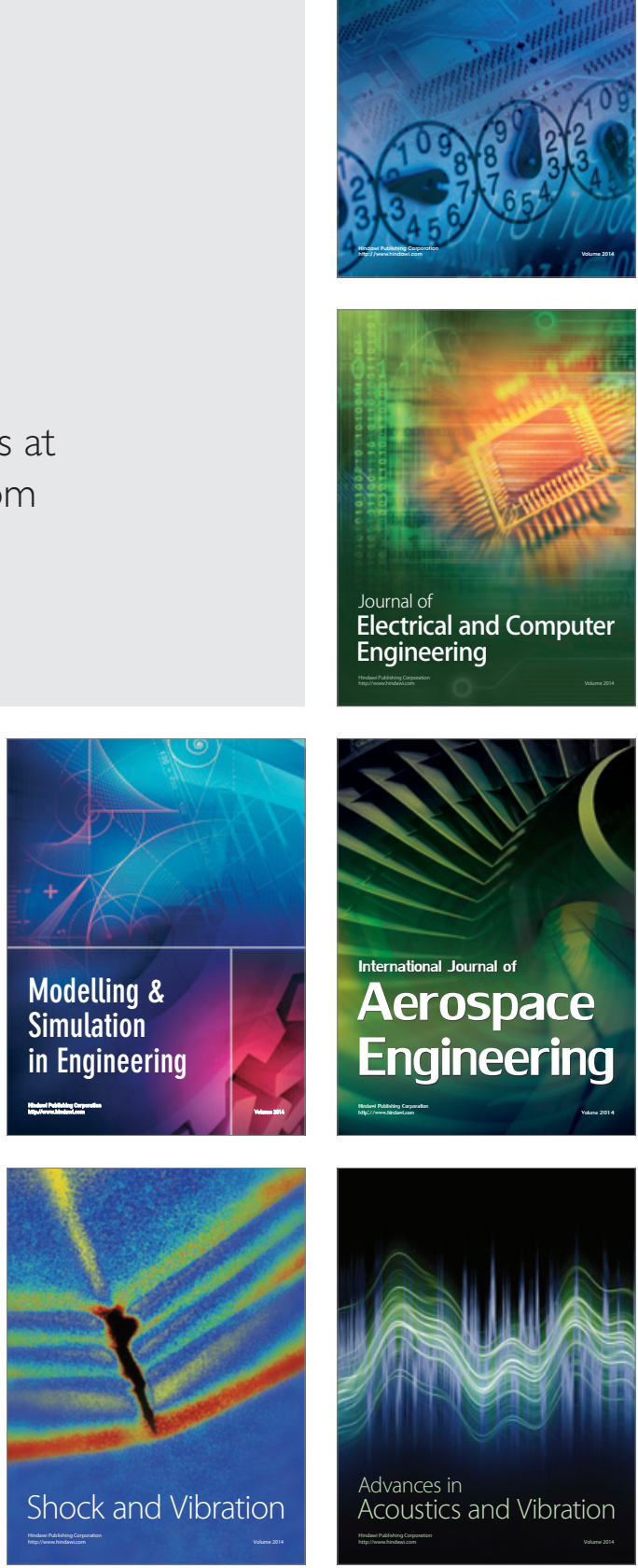